

\section{Internacionalização do Direito: superação do paradigma estatal e a insuficiência de estruturas de diálogos}

\section{Internationalisation of Law: overcoming state paradigm and the insufficiency of dialogue structures}

Marcelo D. Varella ${ }^{1}$

O processo de internacionalização do direito pressupõe novos níveis de interação entre os diferentes atores nacionais e internacionais. De um lado, o direito internacional se forma a partir de novas formas de criação, implementação e controle de normas pelos Estados. De outro, a partir da intensificação de formas de relacionamento entre os atores transnacionais e subnacionais, públicos e privados. O presente trabalho busca analisar este cenário. Trata-se do resultado do aprofundamento por alguns anos do grupo de pesquisa sobre internacionalização do direito. Sistematicamente, o conjunto é dividido em duas partes. A primeira cuida da interação entre os atores não estatais. A segunda, das diferentes formas de relacionamento entre os Estados ou Organizações Internacionais, mas também de atores subnacionais, sobretudo de um tema particularmente importante hoje, o diálogo de juízes.

Os fenômenos estudados na primeira parte apontam para o fortalecimento da interação entre atores subnacionais ou transnacionais. No primeiro caso, trata-se da construção de pontes de acesso para os indivíduos junto aos sistemas internacionais de proteção à pessoa humana, desenvolvido por André Pires Gontijo. Depois, nos três textos seguintes, a construção de conjuntos normativos privados, com pretensão de autonomia, operados contra ou de forma independente aos Estados. Cuida-se da proteção do direito internacional do meio ambiente por meio de instrumentos privados. No terceiro, as formas de interação entre empresas multinacionais e as dificuldades dos Estados em lidar com o fenômeno dos cartéis transnacionais. Por fim, de forma mais geral, a pretensão de autonomia de uma nova lex mercatoria.

Primeiro, em relação ao fortalecimento dos indivíduos em direitos humanos. Nos últimos vinte anos, houve um fortalecimento importante dos tribunais de direitos humanos. Seja no plano multilateral, seja no bilateral, houve a multiplicação de instrumentos de controle. Isso ocorre por meio de diferentes movimentos de expansão: especialização dos núcleos temáticos de proteção dos direitos humanos, com novas estruturas para efetivar o seu controle; e fortalecimento das estruturas de controle já existentes ou criação de novas estruturas, como conselhos ou tribunais internacionais.

No tocante à especialização dos núcleos temáticos, nota-se que há dois momentos bastante distintos na história da proteção internacional da pessoa humana. Em um primeiro momento, que vai até quase os anos 90 , houve a criação e o início dos trabalhos da Comissão de Direitos Humanos da ONU, que exercia controle em torno de alguns poucos tratados, a exemplo da Convenção

Professor do Programa de Mestrado e Doutorado do Centro Universitário de Brasília. Pesquisador do CNPq. Email: marcelodvarella@ gmail.com 
de Direitos Econômicos, Sociais e Políticos e a Convenção sobre Direitos Econômicos, Sociais e Culturais.

A partir dos anos 90, essas duas convenções recebem mecanismos de controle adicionais e novos tratados são criados. Os mecanismos de reforço dos documentos antigos são o Protocolo Opcional de Nova Iorque, de 2008, sobre a Convenção de Direitos Econômicos, Sociais e Políticos, que cria mecanismos de controle; a emenda à Convenção sobre todas as formas de Discriminação Racial, de 1992; e a emenda à Convenção contra todas as formas de Discriminação Contra as Mulheres, de 1999. O número de Estados-parte nesses tratados foi ampliado significativamente após os anos noventa.

Novos tratados são criados e quase todos acompanhados por sistemas de controle próprio, que podem receber denúncias de diferentes pessoas para iniciar seus trabalhos de investigação, oitiva e publicação de pareceres contra os Estados signatários. Destacam-se a Convenção sobre Tortura e Outras Formas Cruéis de Punição, de 2002, ${ }^{2}$ e seus protocolos adicionais que reforçam a imprescritibilidade dos crimes de tortura; a Convenção sobre Todas as Formas de Discriminação Contra as Mulheres, de $1999,{ }^{3}$ e seu protocolo adicional; a Convenção sobre Direitos da Criança, de 1989, e os protocolos adicionais sobre seu envolvimento em conflitos armados, ${ }^{4}$ sobre venda, prostituição ou pornografia, ambos de 2000, e sobre procedimentos de notificação de violações, de 2011; a Convenção sobre a Proteção dos Migrantes e seus Familiares, de $1990^{5}$ e 2008, a Convenção sobre os Direitos das Pessoas Portadoras de Necessidades Especiais, de 2006, e seu protocolo adicional, também de $2006,{ }^{6}$ e a Convenção sobre a Proteção Contra o Desaparecimento Forçado, de $2006 .^{7}$

2 Adotado pela Assembleia Geral, por meio da Resolução 54/200, de 18.12.2002, em vigor a partir de 22.06.2006.

3 Adotado pela Assembleia Geral, por meio da Resolução 34/180, de 18.12.1979, em vigor a partir de 03.09.1981, cujo Protocolo adicional, aberto para ratificação pela Resolução 54/4 de 06.10.1999, apenas entrou em vigor em 22.12.2000.

4 Adotado pela Assembleia Geral, por meio da Resolução 44/25 de 20.11.1989, em vigor a partir de 02.09.1990. Os Protocolos adicionais entraram em vigor respectivamente em 12.02.2002 e 18.01.2002.

5 Adotado pela Resolução 45/158, de 18.11.1990, em vigor em 01.07.2003.

6 Adotado pela Assembleia Geral por meio da Resolução 51.106, de 13/12/2006, em vigor a partir de 03.05.2008.

7 Adotado pela Resolução 61/177, de 20.12.2006, em vigor a partir de 23.11.2010.
Outro movimento foi o fortalecimento dos tribunais internacionais ou criação de novos tribunais. De um lado, houve a ampliação do Corte Europeia de Direitos Humanos e da Corte Interamericana de Direitos Humanos. De outro, a criação de início dos trabalhos da Corte Africana de Direitos Humanos e a recente criação de uma Comissão Intergovernamental de Direitos Humanos da Associação das Nações do Sudeste Asiático.

Todos esses instrumentos de cooperação entre os Estados empoderam atores subestatais, como os indivíduos. Torna-se possível que associações privadas, não governamentais, ou indivíduos atuem contra Estados para resolver conflitos envolvendo a reformulação de políticas públicas nacionais. Em outras palavras, as estruturas internacionais não apenas viabilizam, mas potencializam a ação de grupos não estatais contra os Estados.

O primeiro texto, de André Gontijo, busca analisar as modificações na percepção do indivíduo entre sujeito e objeto de direito internacional. Muito embora não seja considerado como um sujeito pelos diferentes atores, consegue atuar no plano internacional por meio de mecanismos criados pelos sistemas de controle em matéria de direitos humanos. Um primeiro aspecto analisado cuida do direito de peticionamento, um segundo no conceito de vitima, depois a ideia do amicus curiae.

O estudo procura fazer uma análise da jurisprudência europeia, cotejada à luz da prática latino-americana. De fato, nota-se que a experiência europeia serviu de suporte para a consolidação da Corte Interamericana. Contudo, com o passar do tempo, a CIDH criou mecanismos próprios para se fortalecer, que voltaram a influenciar a CEDH nos anos seguintes. Nesse sentido, o autor desenvolve uma visão sobre a possível fragmentação ou maior complexidade do direito internacional dos direitos humanos, a partir de diferentes processos de interação por meio dos indivíduos.

No segundo texto, Gabriela Lima desenvolve uma ideia pouco trabalhada no Brasil: como o direito ambiental pode se concretizar por meio de instrumentos de direito privado, muitas vezes criados pelo Estado, mas em outras, completamente autônomo ou mesmo contrários a práticas Estatais. Concentra-se sobre investimentos estrangeiros. As duas perguntas centrais são os limites e as possibilidades da atuação dos Estados com a proteção dos investimentos estrangeiros. 
$\mathrm{O}$ artigo se desenvolve por meio de alguns estudos de caso, que foram apreciados pelo ICSID (Metalclad v. México, Tecmed v. México e Santa Helena v. Costa Rica). Os casos são o mecanismo para uma discussão teórica de alguns fundamentos do direito internacional, em torno da validade das normas internacionais e para a definição de um objeto para ele. A análise da prática mostra que muitas vezes há incompatibilidade entre as teorias estruturantes do direito internacional e a realidade, o que mostra a necessidade de adaptar e transformar algumas ideias centrais para que o conjunto continue a fazer sentido.

Nesse ponto, a autora analisa diferentes modelos teóricos alternativos, que melhor dão coerência ao direito internacional atual. Passa pelas ideias de pluralismo jurídico e teoria dos sistemas, para caminhar em direção à ideia de maior complexidade do direito internacional, a partir da potencialização dos efeitos de atores privados por meio de instrumentos internacionais, a multitude de racionalidades e de interferências entre diferentes campos jurídicos.

O texto de Karla Margarida Santos continua a discussão da construção do processo de internacionalização por meio do Estado atuando em conjunto ou em reação aos atores privados. Concentra-se no aumento de fluxo de investimentos internacionais, característico do processo de globalização. No entanto, a análise agora porta sobre a insuficiência dos Estados de conseguirem lidar os cartéis internacionais. O objetivo do texto é analisar a necessidade e a efetividade dos instrumentos de cooperação internacional e se eles são meras práticas discursivas, fortemente limitadas pela manutenção de interesses econômicos particulares dos Estados mais influentes.

Nesse sentido, há uma relativização do conceito de soberania, que agora se curva também à atuação de grupos econômicos mais fortes, protegidos por múltiplos Estados. Todo esse cenário levou à necessidade de criação de novos instrumentos de cooperação, em que os Estados cedem informações essenciais e têm que abdicar de parte de sua autonomia de investigação e de punição, em nome de uma ação concertada, a ser operada no plano multilateral.

O texto de Marlon Tomazette é ainda mais focado nos atores privados e discute se haveria uma nova lex mercatoria. Apresenta uma análise mais teórica, que consegue por meio de explicações teóricas e práticas discutir o sur- gimento de um conjunto de normas, com pretensão de autonomia em relação ao direito estatal, a partir da lex mercatoria. A nova lex mercatoria seria o resultado dos múltiplos processos de integração normativa infraestatal ou transnacional, como a coordenação por intercruzamentos normativos e jurisprudenciais, a harmonização por aproximação, a unificação com os sistemas de integração, entre outros. Assim, da análise dos casos à teoria geral, a primeira parte, centrada em atores não estatais, avalia os limites do paradigma estatal como fundamento do direito vigente no âmbito internacional nos dias de hoje.

A segunda parte da obra é tão inovadora quanto à primeira. Agora, concentra-se em interações entre atores estatais ou subestatais. Parte-se de uma análise mais geral, de internacionalização do direito após a destruição de muitas barreiras nacionais, uma particularidade dos Estados colapsados, objeto de ingerência das Nações Unidas. Na mesma linha, discutem-se em seguida algumas opções da comunidade internacional para punir os responsáveis por crimes de guerra, de forma a evitar a escalada do sentimento de insatisfação das comunidades atingidas.

As interações, entretanto, nem sempre são positivas ou mesmo ocorrem. Os textos seguintes criticam diferentes aspectos do processo e apontam suas falhas, no plano subnacional ou interestatal. Analisam-se as dificuldades da interação entre juízes, os obstáculos para integrar determinados temas, até o domínio de algumas potências sobre a construção de um novo direito global.

Em relação ao primeiro texto, de Christiani Buani, destaca-se o conceito de "justiça de transição", como sendo aquela aplicável a sociedades de pós-conflitos armados. Nota-se a tentativa de formação de redes administrativas em múltiplos níveis para construir novos modelos de justiça, com base em experiências importadas de diferentes países que participaram do processo de ingerência. Como era de se esperar, a mescla de diferentes modelos implementados em culturas fragilizadas demonstram no médio prazo baixa efetividade.

Em países destruídos por conflitos armados de ampla escala, após a ingerência das Nações Unidas, notase que o modelo adotado segue certa constância: os Estados que participaram dos conflitos exportam modelos de estruturas administrativas que consideram adequadas, ou seja, uma globalização hegemônica de grandes potências. Há vários problemas: primeiro, as estruturas locais 
têm dificuldade em filtrar as experiências para construir instituições que lhes sejam mais úteis, de acordo com suas culturas; segundo, a existência de múltiplos modelos de inspiração distintos leva à falta de diálogo entre as diferentes soluções importadas; terceiro, muitas vezes, mesmo as melhores experiências não trazem soluções possíveis em Estados que estão em momentos distintos, com todas as características sociais mais importantes muito distantes daquelas que estão sendo importadas.

Em seguida, analisa-se um caso específico, mais voltado para o direito penal internacional: a justiça restaurativa em Uganda. Uganda foi palco de um conflito interno em larga escala, que gerou a atuação do Tribunal Penal Internacional.

O texto de Raquel Tiveron analisa a questão da justiça restaurativa em Uganda. O conflito em Uganda, provocado pelas disputas de poder envolvendo Musevini e o Lord's Resistance Army causou dezenas de milhares de mortes, atingindo países vizinhos como Sudão do Sul (então parte do Sudão) e Congo. Ao total, estima-se que os conflitos tenham gerado aproximadamente um milhão de refugiados.

A construção da paz na região foi desenvolvida por dois movimentos distintos: no plano nacional e no plano internacional. No plano doméstico, aprovou-se uma lei de anistia, com perdão a todos os cidadãos envolvidos no conflito, desde 1986. No plano internacional, estruturas internacionais em absorver mecanismos distintos daqueles dos países hegemônicos para promover a paz no âmbito africano.

Passa-se em seguida à discussão das interações diretas entre atores subnacionais. Ruitemberg Nunes Pereira discute a proposta de um "diálogo entre juízes", para criticar que exista de fato uma interação horizontal, plural na construção de uma sociedade democrática global, como pretendem alguns teóricos. Na visão do autor, nota-se a criação de um mercado de ideias, no sentido em que há um conjunto de valores criados e "vendidos" por determinados Estados mais influentes e consumidos pelos demais países do mundo. Os principais fornecedores de valores civilizatórios continuam a ser alguns Estados europeus, sobretudo França, Alemanha e Reino Unido, além dos Estados Unidos, o que varia conforme o tema.

O texto se fundamenta em diferentes aspectos da realidade. De um lado, nota o fluxo de referências cruzadas entre os tribunais, bem como a qualidade de alguns casos analisados. De fato, como aponta o autor, os tribunais dos países acima se citam bastante e são fontes continuas dos demais Estados, mas ignoram o desenvolvimento intelectual nos tribunais "periféricos". Mesmo entre os principais órgãos internacionais de solução de conflitos, nota-se uma assimetria importante, de fato, e não de direito, o que mostra a construção de um monólogo de cortes, mais do que um diálogo.

Nesse sentido, o autor aponta alguns problemas com a visão de autores liberais que consideram a existência de construção de redes de relacionamento entre atores subnacionais, sobretudo de países democráticos. A interpretação da realidade não caminharia para a construção de relações mais democráticas globais, mas na construção de novas formas de colonialismo cultural.

Passa-se, então, a mais um texto crítico, de Geilza Cavalcanti Diniz. A análise segue na mesma linha dos artigos anteriores, que discutem limites do processo de internacionalização do direito. O foco, no entanto, agora, é a dificuldade de construir instrumentos de diálogo sobre temas relacionados a elementos nucleares das culturas locais, como o direito à vida e à religião. O exemplo analisado é o caso do aborto. O fio condutor lógico segue primeiro com a descrição de alguns ordenamentos nacionais, de forma a apontar diferenças importantes existentes hoje. 
Em seguida, a autora analisa diferentes estudos de jurisprudência, para verificar quais os argumentos utilizados pelos juízes para construir pontes de diálogo ou realçar divergências entre os tribunais. Os casos analisados são interessantes por trabalhar o tema em uma zona cinza, que coloca em xeque a racionalidade moderna e elementos religiosos. O caso central do capítulo, o aborto dos anencéfalos, foi escolhido de forma exemplar, pois revela, mesmo dentro de tribunais dos países centrais, certa tensão entre diferentes percepções. Os países escolhidos: Holanda, Argentina e Brasil demonstram como o problema foi abordado de forma distinta em um país do Ocidente e dois Estados do extremo Ocidente. Em si, os antagonismos encontrados revelam dificuldades da construção de processos de diálogos em temas sensíveis.

Carla Patrícia Lopes caminha no mesmo sentido. Em vez de fazer uma analise comparativa, busca analisar um caso especifico no Brasil, relacionado à liberdade de imprensa. $\mathrm{O}$ artigo se inicia com uma reflexão de diferentes modelos teóricos para produção do direito em um ambiente de pluralismo e transconstitucionalismo. Assim, alguns autores chaves para a compreensão do fenômeno, como Mireille Delmas-Marty e Marcelo Neves servem de base de argumentação do pano de fundo teórico. A autora busca, na teoria geral analisada na primeira parte desse livro, elementos que demonstram os diferentes fenômenos de diálogo entre juízes e os limites apresentados na construção do processo de internacionalização do direito.

O estudo de caso neste capítulo tem um objetivo distinto. Busca analisar o tema de diálogo entre juízes, em uma lógica de heterarquia de influências. O tema, já colocado em discussão em diferentes países, coloca em xeque duas posições difíceis: o direito constitucional de liberdade de imprensa versus o direito de privacidade. $\mathrm{O}$ exemplo se torna interessante porque, em vários países onde foi analisado, usa-se a jurisprudência estrangeira para construir as bases para o julgado e, sobretudo, porque não há posição pacífica no plano internacional. Ao contrário do exemplo anterior, marcado pelas dificuldades de interação pelas diferenças culturais refletidas em julgados concretos, aqui, as peculiaridades dos casos concretos diferentes servem de argumento para estimular um diálogo e não para afastá-lo.

Por fim, Alessia Chevitarese fecha o conjunto de textos com um capítulo com uma discussão de teoria geral. Parte da pergunta "quem governa o direito?". Constrói a resposta a partir dos argumentos desenvolvidos no livro e de alguns autores clássicos que servem de fundamento comum aos vários capítulos apresentados. Assim, os argumentos de Norberto Bobbio, Jose Eduardo Faria, Hans Kelsen e Verdross são analisados à luz do que hoje chamamos internacionalização do direito. O capítulo caminha pela apresentação da justificativa de validade e legitimidade de normas no plano internacional.

O objetivo da autora é verificar se as tradicionais estruturas de explicação do direito internacional são suficientes para explicar os novos processos de internacionalização. A autora considera que há limites importantes nas teorias clássicas e passa a analisar novos autores como teoria dos sistemas, em Luhmann e Teubner, e outras visões distintas, que poderíamos chamar de mistas, como Mireille Delmas-Marty, Nickel e Jurgen Habermas, que hoje teriam melhores argumentos para dar uma coerência às diversas manifestações de direito dentro de uma lógica de globalização.

Assim, o conjunto de textos traz uma visão interessante, com base nos autores que são atualmente considerados os melhores na área, para discutir como o processo de globalização altera a construção do fenômeno jurídico contemporâneo. Trata-se de uma obra refletida, discutida ao longo de vários anos, entre doutorandos em Direito, com ampla experiência de docência e prática relacionada com o que escrevem. Por tudo isso, acreditamos que se trata de um trabalho que pode ser útil à compreensão e à disseminação do debate qualificado no Brasil. 
Para publicar na Revista de Direito Internacional, acesse o endereço eletrônico www.rdi.uniceub.br ou www.brazilianjournal.org.

Observe as normas de publicação, para facilitar e agilizar o trabalho de edição. 